\title{
Aspectos (não)contribuintes do Pibid para a formação docente de graduandos em Letras Inglês: um estudo de caso
}

Joel Victor Reis Lisboa*

Recebido em: 28/05/2019

Aceito em: 12/11/2019

Resumo: Este artigo investiga, mediante a análise qualitativa de questionários e relatos de experiência, de que maneira a atuação no Pibid modificou a formação docente de graduandos em Letras Inglês da UFG-REJ, analisa se os objetivos do subprojeto foram alcançados e reflete sobre as impressões dos bolsistas acerca de suas experiências. Os dados obtidos evidenciaram contribuições consideráveis para a prática docente, como o fomento da articulação teoria/prática e oportunidade de vivência e reflexão no contexto educacional público. Todavia, identificou-se certa carência de orientações didático-pedagógicas anterior ao adentramento em sala de aula como um aspecto não-contribuinte, ocasionando sentimentos desmotivadores nos bolsistas.

Palavras-chave: Pibid. Formação docente. Atuação e reflexão docente.

Abstract: This paper investigates, through the qualitative analysis of questionnaires and experience reports, how participating in Pibid have modified teacher education of UFG-REJ English Language and Literature undergraduates, as well as to analyze whether the subproject goals were achieved and to reflect on scholars' impressions towards their experiences. The data indicate substantial contributions to teacher training, such as reinforcement of theory/practice articulation and opportunity to experience and reflect on public educational context. Nevertheless, a lack of didactic-pedagogical guidelines prior to the first contact with the classroom was identified as a non-contributing aspect, leading to demotivating feelings.

Keywords: Pibid. Teacher training. Teaching action and reflection.

Resumen: Este artículo investiga, mediante el análisis cualitativo de cuestionarios y relatos, cómo actuar en el Pibid modificó la formación docente de graduandos en Letras Inglés de la UFG-REJ, analizar si los objetivos del subproyecto fueron alcanzados y reflexionar sobre las impresiones de los becarios sobre sus experiencias. Los datos evidenciaron contribuciones considerables a la práctica docente, como el fomento de la articulación teoría/práctica y la oportunidad de vivencia y reflexión en contexto educativo público. Sin embargo, se identificó cierta carencia de orientaciones didáctico-pedagógicas anterior al contacto con el aula como un aspecto no contribuyente, ocasionando sentimientos desmotivadores en los becarios.

Palabras clave: Pibid. Formación docente. Actuación y reflexión docente. 


\section{Introdução}

Crenças acerca da impossibilidade da aprendizagem de línguas estrangeiras (doravante LEs) em âmbito público escolar são recorrentes no discurso de gerações de pais, alunos e até de profissionais da área da educação (ASSIS-PETERSON; COX, 2007; BARCELOS, 2007). Diante disso, a formação inicial sólida de professores críticoreflexivos é relevante para ressignificar tais crenças a partir da transformação do ensino/aprendizagem de LE nesse contexto educacional. Não obstante, segundo Coelho (2005), o número de professores de línguas que se encontram desanimados, frustrados e com seu trabalho limitado devido ao prejuízo social e histórico que a educação brasileira vem sofrendo é grande.

Paralelamente à crença sobre a aprendizagem de LE nas escolas públicas, a consciência sobre a importância do domínio de ao menos uma LE aumenta cada vez mais. Um dos motivos é a exigência para fins empregatícios e/ou acadêmicos, em que é exigido que profissionais de diferentes áreas saibam comunicar-se sistematicamente com diferentes grupos culturais. Nesse contexto, a língua inglesa (doravante LI) desempenha o papel de língua franca (JENKINS, 2012) no âmbito dos negócios, da economia, da ciência, da tecnologia, da informação, do turismo, dentre outras áreas. Outros fatores que corroboram a importância da LI é a globalização e a revolução informacional e tecnológica (LEFFA, 2011; FADANELLI; MONZÓN, 2017), cujos avanços "tornam o mundo pequeno e interconectado por vários meios, sugerindo-nos a ideia de que vivemos em uma aldeia global" (LIBÂNEO; OLIVEIRA; TOSCHI, 2003, p. 66).

Em vista disso, o ensino/aprendizagem de LI nas escolas públicas é imprescindível, visto que desempenha um papel de suma importância na medida em que leva o conhecimento e a informação do centro para a periferia e/ou vice-versa, ampliando, assim, os limites da educação (LEFFA, 2003). Destarte, o domínio de LI se torna um meio de abertura de portas para oportunidades na vida escolar e profissional, pois:

Em um mundo cada vez mais dividido entre aqueles que têm acesso à informação e a conhecimento em escala mundial, e, portanto, a maiores 
oportunidades de aprender, e aqueles que vivem limitados a informações e conhecimentos locais, e, portanto, a menores chances de ampliar seus horizontes, a aprendizagem de inglês se transformou em um dos instrumentos centrais da educação contemporânea (MOITA LOPES, 2005, p. 2).

É nesse cenário que se apresenta o subprojeto Language and Literature, produto da parceria entre o Colégio Estadual Marcondes de Godoy e o curso de Letras/Inglês da Universidade Federal de Goiás - Regional Jataí (UFG-REJ) no âmbito do Programa Institucional de Bolsas de Iniciação à Docência (Pibid), contexto em que ocorre a aproximação de futuros professores de LI ao âmbito público de ensino, potencial local de trabalho ou futuro local de trabalho não somente dos participantes do subprojeto, mas de alunos de cursos de licenciatura em geral.

O Pibid, apoiado pelo Ministério da Educação e pela Coordenação de Aperfeiçoamento de Pessoal de Nível Superior (CAPES), ao passo que contribui para a aproximação entre o ensino superior e a esfera pública de educação, tem como objetivo central incentivar a formação docente para a educação básica.

Nesse sentido, o referido programa promove a inserção e atuação de discentes dos cursos de licenciatura no cotidiano das escolas públicas, possibilitando a reflexão, ainda em período de graduação, sobre o papel e a prática docente nesse contexto educacional. Ademais, o Pibid incentiva a colaboração das escolas públicas e de seus professores na formação inicial dos participantes dos subprojetos, no sentido de atuarem como "protagonistas dos processos formativos dos estudantes das licenciaturas, mobilizando seus professores como coformadores dos futuros professores" (MATEUS; EL KADRI; GAFFURI, 2011, p. 372).

Por meio de parcerias como essas, em que são desenvolvidas atividades de caráter educativo, cultural e científico, "uma relação transformadora entre a universidade e a sociedade" (SUGIMOTO, 2007, p. 9) se torna realidade, contribuindo para a indissociabilidade entre ensino, pesquisa e extensão, princípio fundamental das universidades brasileiras (MOITA; ANDRADE, 2009). Outrossim, é relevante ressaltar que programas como o Pibid, ao passo que investem na formação inicial e continuada para o magistério, fomentam a transformação do cenário educacional público, como discutido por Audi et al (2013): 
Atualmente o cenário educacional parece demonstrar que o Governo Federal e alguns governos estaduais acenam para o reconhecimento dessa necessidade de mudança na formação de professores ao propor ações para aproximação desses dois mundos - a universidade e a escola pública (AUDI et al, 2013, p. 80).

Portanto, o Pibid é um instrumento fundamental para promover o estreitamento de vínculos entre ensino superior e educação básica e, por conseguinte, consolidar as bases da formação docente, almejando o sucesso da educação pública de qualidade.

Diante do exposto, e considerando o propósito central do Pibid que consiste na valorização da formação de professores para magistério nas escolas públicas, o objetivo do presente artigo consiste em investigar, por meio de questionários e relatos de experiência, se o subprojeto Language and Literature da UFG-REJ, modificou a formação docente dos bolsistas atuantes na escola parceira, e caso sim, de quais formas e em que âmbito essas modificações ocorreram. Por conseguinte, buscamos analisar se as ações previstas/objetivos presentes no plano de trabalho do subprojeto foram alcançadas, bem como refletir sobre as impressões dos bolsistas em relação às vivências/experiências promovidas pelo subprojeto no âmbito do Pibid.

Na seção seguinte introduzimos o subprojeto e a escola parceira, de modo a contextualizar a pesquisa e, na sequência, apresentamos a metodologia do presente trabalho. Em seguida, os resultados obtidos por meio da análise do plano de trabalho e dos questionários e relatos de experiência dos bolsistas serão apresentados e discutidos.

\section{O subprojeto Language and Literature}

O Colégio Estadual Marcondes de Godoy, escola parceira do subprojeto Language and Literature, fica localizado na área central da cidade de Jataí-GO, fator que viabiliza o atendimento a 395 alunos moradores de diversos bairros da cidade. No período matutino, a escola atende aos alunos do ensino médio e no vespertino aos alunos do ensino fundamental II. 
Com a supervisão e o auxílio do professor coordenador e do professor supervisor do subprojeto, os bolsistas realizam atividades, celebrações e oficinas interativas concernentes a tópicos relevantes em LI, assim como tangentes às culturas de países anglófonos, tendo em vista o letramento linguístico e cultural dos alunos. A partir do segundo semestre de 2016, essas oficinas foram voltadas para o Exame Nacional do Ensino Médio - Enem, visando preparar os alunos do ensino fundamental II e, principalmente, do ensino médio para a seção de LI do exame.

Além das atividades, festividades e oficinas, os graduandos bolsistas também oferecem monitorias em contraturno na escola parceira, com o intuito de auxiliar alunos que tenham dificuldades ou curiosidades relacionadas à LI. Nesse ensejo, os bolsistas oferecem auxílio tangente a diversos aspectos do inglês, como problemas relacionados à gramática, escrita, pronúncia, dúvidas sobre conteúdos estudados durante o ano letivo e também prestam auxílio na realização de deveres de casa e trabalhos escolares.

Tendo em vista o intuito do presente artigo, se faz relevante analisar as ações previstas/objetivos presentes no plano de trabalho do subprojeto Language and Literature. Das vinte e duas ações previstas/objetivos, listadas das letras A a Q, interessanos apenas os oito que se seguem, por serem relacionados/as diretamente aos alunos bolsistas participantes do subprojeto:

1) Realização de estudos teóricos nas áreas de ensino de língua inglesa e de literaturas de língua inglesa, seguidos de encontros pedagógicos para discussão, de forma a permitir aos bolsistas a incursão teórica e o estabelecimento de relação com a sua atuação no projeto e futura profissão;

2) Oferecimento de cursos e oficinas temáticas, estabelecidas de acordo com os interesses dos alunos da escola parceira. Esta ação envolve o planejamento de atividades em oficinas/cursos, com objetivos claros; planejamento de material didático adequado ao nível dos alunos; trabalho em equipe; desenvolvimento da habilidade de gerenciamento de sala de aula; uso eficiente dos recursos impressos e tecnológicos;

3) Realização de pesquisas de cunho pedagógico, para o levantamento dos interesses, necessidades e feedback do alunato da escola parceira, de forma a atender às reais demandas dos alunos e da escola, com ações de primeira qualidade, e prover recurso para reflexão contínua dos bolsistas;

4) Organização de momentos de observação, negociados com os professores responsáveis pela disciplina de língua inglesa e de outras disciplinas exploradas nos textos literários propostos, de forma a viabilizar a interdisciplinaridade e transdisciplinaridade, assim como o estabelecimento da relação teoria/prática; 5) Acompanhamento e avaliação das atividades dos bolsistas, buscando o princípio ação-reflexão-ação (SCHÖN, 20oo), por meio de: a) reuniões quinzenais deles com a coordenadora do projeto, supervisor e professores de língua inglesa, para análise das ações desenvolvidas e determinação de diretrizes 
para as ações futuras; b) elaboração de relatórios escritos mensais e semestrais dos bolsistas c) pesquisas de satisfação desenvolvidas entre os alunos da escola; 6) Elaboração de material didático para a escola, conforme as necessidades apontadas pelos professores, alunos e bolsistas, dando a esses a oportunidade de estabelecimento de uma conexão clara entre a teoria estudada no decorrer do Curso de Letras com a prática pedagógica na escola parceira, no que tange à seleção e elaboração de materiais didáticos;

7) Participação em eventos científicos, com publicação de resumos e trabalhos completos em eventos, oferecendo aos bolsistas uma oportunidade ímpar de reflexão sobre sua experiência, e divulgação, em escrita científica, do seu trabalho;

8) Avaliação da aprendizagem dos alunos da escola parceira pelos bolsistas e professores, buscando a reflexão-ação-reflexão da equipe, a fim de promover e aprimorar a formação de um professor reflexivo, qualificado, questionador e capaz de intervir positivamente na educação básica, na avaliação do rendimento de alunos de inglês, e na discussão e posicionamento crítico acerca do ensino de inglês como língua estrangeira e de suas literaturas (UNIVERSIDADE FEDERAL DE GOIÁS, 2013, p. 2-3).

A análise do plano de trabalho do subprojeto em questão é relevante no sentido de viabilizar a confrontação das ações previstas/objetivos com os dados obtidos por meio da análise dos questionários e relatos de experiência, permitindo analisar se a edição do subprojeto em questão atendeu às expectativas previstas no plano de trabalho, principalmente no que tange à formação docente e à preparação dos bolsistas para a realidade do âmbito público educacional.

\section{Metodologia}

O presente trabalho tem como metodologia uma pesquisa qualitativa, cujo corpus é constituído pelo plano de trabalho do subprojeto em questão, bem como questionários e relatos de experiência redigidos pelos alunos bolsistas. De acordo com Dörnyei (2007), pesquisas qualitativas como essa focam em descrever, entender e esclarecer aspectos da experiência humana. Outrossim, considerando que o intuito do artigo consiste em investigar um subprojeto específico, sem a pretensão de estabelecer generalizações a partir dos resultados obtidos, ele se configura como um estudo de caso, pois visa entender a natureza e aspectos intrínsecos de um caso particular (DÖRNYEI, 2007).

A escolha por se trabalhar com questionários além dos relatos de experiência se deu, pois o uso destes implica em economia de tempo, pelo fato de atingir um maior número de pessoas simultaneamente, além de permitir a obtenção de respostas mais 
rápidas e precisas. Outro fator importante é que por decorrência do anonimato ao qual os entrevistados se enquadram, há maior liberdade de respostas e mais segurança no que tange à identificação dos alunos bolsistas (MARCONI; LAKATOS, 2003).

Os sujeitos da pesquisa são cinco bolsistas do subprojeto Language and Literature que possuem entre 18 e 25 anos de idade, sendo representados por nomes fictícios escolhidos por eles, tendo em vista preservar suas identidades.

Os questionários foram compostos por duas seções. A primeira continha oito perguntas abertas relacionadas aos seguintes pontos: (i) motivações dos discentes para ingressar no curso de Letras Inglês e no subprojeto do Pibid; (ii) expectativas anteriores à participação no subprojeto; (iii) experiências tangentes à língua inglesa e à docência e, por fim (iv) a avaliação dos discentes sobre o subprojeto.

A segunda seção era composta por quinze afirmações voltadas à aspectos (não)modificadores concernentes ao Pibid, como por exemplo: "O Pibid não me despertou interesse pela docência", "Me sinto mais preparado para a docência do que quando ingressei no subprojeto" e "Há preparação teórico-metodológica para o ensino de línguas”. Os alunos tinham quatro opções para assinalar a que melhor representasse seu posicionamento, sendo elas: concordo totalmente, concordo, discordo e discordo totalmente. Na sequência de cada afirmação, havia um espaço para que os discentes justificassem suas respostas por extenso.

No que tange ao relato de experiência, foi pedido para que eles escrevessem um texto em formato de narrativa discorrendo sobre sua experiência no âmbito do Pibid. As seguintes diretrizes foram passadas aos alunos:

(i) Relate como se deu seu primeiro contato com a sala de aula como docente antes de participar do Pibid (se houve) ou após o ingresso no subprojeto. Houve mudanças na prática ou reflexão docente após seu ingresso no Pibid?

(ii) Comente as impressões que você tinha sobre o ensino de línguas antes de participar do Pibid. Algo mudou desde seu ingresso no subprojeto?

(iii) Relate experiências vivenciadas no Pibid que você considera relevantes ou positivas e outras consideradas irrelevantes ou negativas para a sua vida 
profissional e acadêmica. Comente se elas modificaram ou não a sua experiência docente.

(iv) Você se sente preparado para atuar como professor após sua participação no Pibid?

Para melhor organização na apresentação dos resultados, os dados foram estruturados em categorias temáticas, dentre as quais foram enfatizadas as que ocorreram com maior frequência nos questionários e relatos de experiências analisados, assim como as que se relacionam à formação docente. Alguns dos excertos extraídos do corpus se enquadram em mais de uma categoria, portanto, estarão enumerados de forma a facilitar a localização.

\section{Resultados e discussão}

Nesta seção, os dados analisados serão apresentados seguindo um procedimento de análise qualitativa e análise de conteúdo. Em um primeiro momento, as experiências dos sujeitos da pesquisa anteriores à atuação no subprojeto, bem como suas expectativas quanto a essa participação, serão apresentadas. Em seguida, as vivências no âmbito do subprojeto narradas pelos próprios alunos bolsistas serão evidenciadas, e a partir dos excertos dos questionários e relatos de experiências, reflexões tangentes à formação docente, ao subprojeto e às impressões dos alunos bolsistas serão desenvolvidas.

\section{Experiências prévias em sala de aula}

A análise dos dados nos mostra, inicialmente, uma diversidade no que condiz à experiência prévia em sala de aula dos participantes da pesquisa. Essa experiência $a$ priori pode influenciar a forma como o indivíduo analisa e compreende as vivências e o contexto de ensino/aprendizagem em que está adentrando.

Dentre os cinco bolsistas, apenas dois já haviam tido experiência docente anteriormente ao Pibid. Helena (excerto 1) ministrara aulas para uma turma de educação 
infantil, ao passo que Simão (excerto 2) participara como professor voluntário em um projeto durante o ensino médio, como podemos ver nos excertos a seguir:

(Excerto 1) Meu primeiro dia em uma sala de aula poderia ser descrito como confuso. Senti-me completamente perdida, já que, até então, eu nunca tinha dado aula antes. Meus alunos eram crianças de entre três e quatro anos de idade que possuíam fôlego para correr e brincar o dia todo e nada os fazia sentar e prestar atenção (Helena, relato de experiência).

(Excerto 2) Em meu colégio existia o Protagonismo Juvenil, que colocava o aluno como protagonista. Abri o protagonismo para ensinar a língua japonesa, ou pelo menos uma pequena parcela dela. [...] A priori achei que era só chegar e falar um monte de curiosidades e tudo estava resolvido, [...] eu não havia planejado nada e como era de se esperar, a aula foi um fracasso (Simão, questionário e relato de experiência).

Dessa forma, nota-se que o primeiro contato com a sala de aula se deu na ausência de orientações prévias e de pressupostos teórico-metodológicos, o que resultou numa primeira aula desestruturada, sem objetivos, meios e fins, ocasionando sentimentos de frustração (excerto 2) e confusão, além de dificuldades em administrar a atenção dos alunos (excerto 1). Nesse sentido, se faz necessária uma maior preparação dos graduandos anteriormente ao adentramento em sala de aula, de forma que tenham conhecimento e domínio de pressupostos teórico-metodológicos e didáticos, e que o contato se dê sob a luz da articulação entre teoria e prática (MELLO, 200o; VOLKMAN; MENDES; BACCON, 2016), para que, dessa forma, a experiência tanto dos alunos quanto dos professores seja agradável e produtiva.

Essa oportunidade de vivenciar/experienciar o cotidiano das escolas ainda em período de graduação, oportunizada pelo Pibid, pode auxiliar o professor-estudante a desenvolver criticidade e traçar reflexões no que tange à realidade e superação de desafios da prática pedagógica no âmbito público educacional.

\section{Expectativas prévias}

Se fez importante questionar os bolsistas acerca das expectativas que tinham anteriormente à participação no subprojeto para, posteriormente, analisar se houve algum aspecto modificador resultante da participação no subprojeto em questão. No que tange ao questionamento referente às expectativas anteriores ao subprojeto, foi possível 
distribuir as respostas em duas categorias: a) Experiência em sala de aula e b) Fomento da prática docente.

Sendo assim, três dos bolsistas responderam que a expectativa que tinham era acerca da experiência em sala de aula, de como se dariam as relações interpessoais no âmbito público de ensino e da oportunidade de aprender mais. Outros dois bolsistas tinham expectativas acerca do desenvolvimento de sua prática docente, especialmente no que tange à elaboração de planos de aula e aperfeiçoamento didático, como é possível interpretar a partir dos seguintes excertos:

(Excerto 3) As minhas expectativas foram sobre o contato com a sala de aula, como seria esse contato e se daria certo (April, questionário).

(Excerto 4) As minhas expectativas eram em relação a ter mais experiência dentro de sala de aula (Helena, questionário).

(Excerto 5) Minhas expectativas eram que eu iria aprender muito tendo contato com a sala de aula e que a bolsa iria me ajudar financeiramente a me manter na cidade de Jataí (Maria, questionário).

(Excerto 6) Acreditava que haveria aulas sobre como fazer plano de aula, como conseguir a atenção dos alunos sem ir ao extremo, porém não foi isso o que ocorreu, na minha visão fomos praticamente jogados dentro da sala de aula, sem a mínima ideia do que fazer. [...] O Pibid não é o que eu esperava, eu tinha mais expectativas (Furtado, questionário e relato de experiência).

(Excerto 7) Pensei que eu receberia orientações para melhorar as aulas, mas a realidade foi um pouco diferente quando me colocaram para dar aulas com mais quatro alunos. Não que eles sejam ruins, eram muito bons, era aí que estava o problema. Os alunos perdem a confiança no professor novo pois eles sabem que este professor é inexperiente (Simão, questionário).

Um fator de contribuição social do Pibid fica muito claro no excerto 5, no que concerne ao auxílio financeiro dado ao estudante de graduação de modo que consiga se envolver de forma mais produtiva em atividades acadêmicas. É histórico o fato de que os candidatos a vagas em cursos de licenciatura geralmente vêm de classes sociais mais baixas em relação à pirâmide social (GATTI, 1996). Portanto, muitos são obrigados a procurar empregos que não estão relacionados à sua área de formação para sustento próprio. Nesse sentido, as bolsas acadêmicas permitem maior comprometimento do aprendiz com a área de conhecimento escolhida.

Em relação aos outros aspectos levantados por Furtado e Simão nos excertos 6 e 7, respectivamente, esses serão abordados no tópico seguinte por abranger tanto as 
expectativas prévias quanto as experiências contribuintes e não contribuintes relacionadas ao subprojeto.

\section{Aspectos (não)contribuintes para a formação docente}

Além do fomento financeiro apresentado anteriormente, não podemos deixar de observar os relatos de Furtado e Simão (excertos 6 e 7), em que os dois bolsistas evidenciam a ausência de orientações didáticas anteriormente ao primeiro contato com a sala de aula no âmbito do subprojeto, fazendo com que se sentissem despreparados e frustrados.

Assim como Furtado e Simão, outros bolsistas relataram essa falta de preparo anteriormente ao primeiro contato com a sala de aula no subprojeto, como podemos observar nos excertos seguintes:

(Excerto 8) Quando entrei no Pibid eu era caloura, não tinha contato com a sala de aula e não fazia a menor ideia de como seria. Como fui jogada lá sem saber nada o que eu aprendi veio do fato de eu correr atrás dos meus veteranos e de outros professores em busca de ajuda. [...] Ainda me lembro da primeira aula que participei no Pibid, eu não sabia o que fazer e deixei meu veterano fazer praticamente tudo sozinho. Mas com o tempo fui pegando o jeito, aprendi a lidar com mais de 30 alunos em uma sala, fazer com que o ambiente ficasse confortável entre eu e eles (April, questionário e relato de experiência).

(Excerto 9) A minha primeira aula ministrada no colégio já fazendo parte do Programa foi outro desafio, já que meus antigos alunos eram crianças e os do Programa são adolescentes, e também porque não fui orientada sobre como elaborar ou aplicar uma aula, mas mesmo assim, eu, junto à outra bolsista que ministrou a micro aula comigo, conseguimos dar a matéria pedida pelo professor (Helena, relato de experiência).

Ainda sobre o primeiro contato com o ambiente educacional no âmbito do subprojeto, Simão continua seu relato do excerto 7 :

(Excerto 10) Achei proveitoso passar por essa experiência pois me mostrou que eu ainda sou inexperiente. Acho que esse momento é aquele em que o professor iniciante fica apavorado e não gosta da sala de aula logo de início (Simão, relato de experiência).

No que tange aos excertos 6 ao 10, é relevante compreender que permitir que professores em formação adentrem a sala de aula desprovidos de preparo teóricometodológico prévio e não se sentindo confortáveis e capacitados quanto ao domínio da prática docente, faz emergir uma face do subprojeto que não vai de encontro aos 
objetivos gerais do Pibid, que consistem justamente na preparação de professores em formação para o magistério. Por conseguinte, essa falta de preparo a priori faz com que os professores bolsistas do subprojeto se sintam desmotivados e frustrados, sentimentos que suscitam dificuldades no andamento do subprojeto na escola parceira, visto que podem não se sentir confortáveis em oferecer as monitorias, dinamizar as atividades e oficinas, ou seja, podem se sentir desmotivados e incapazes de desenvolver grande parte do trabalho do subprojeto na escola parceira.

Outrossim, é possível perceber mudanças de comportamento oriundas da ausência de preparação/orientação anteriormente ao primeiro contato com a sala de aula, como rigidez ao lidar com os alunos e apreensão demasiada, fazendo com que os discentes se sintam impotentes frente à sala de aula, como é possível notar nos excertos a seguir:

(Excerto 11) Me tornei um pouco mais rígida para com os alunos, pois alguns não se comportam. [...] A partir daí [do primeiro contato com a sala de aula] resolvi que se eu quisesse continuar dando aulas eu teria que me tornar uma professora rígida e não mais dinâmica como eu era e pretendia continuar sendo (Maria, questionário e relato de experiência).

(Excerto 12) Eu ainda tenho aquele medo de errar na sala de aula, ou de o aluno fazer uma pergunta que eu não saiba a resposta, e quando os alunos estão conversando sinto que estou invisível dentro da sala de aula (Furtado, questionário).

Portanto, a partir dos excertos 11 e 12, podemos observar que o contato com a sala de aula sem orientação adequada faz emergir noções distorcidas no que tange à prática docente e, principalmente, ao "mau comportamento" dos alunos, acarretando em rigidez em relação ao comportamento dos discentes, apreensão demasiada e sentimentos de invisibilidade, aspectos evidenciados por Maria e Furtado.

Não obstante, uma preparação teórico-metodológica adequada possibilitaria uma mudança de perspectiva dos bolsistas em relação à "indisciplina” dos alunos e à visão do ensino fundamentado em autoritarismo, haja vista que, nas palavras de Freire (1996, p. 36), "a disciplina verdadeira não existe na estagnação, no silêncio dos silenciados, mas no alvoroço dos inquietos, na dúvida que instiga, na esperança que desperta”. Em outras palavras, a inquietude pode ser favorável para o ambiente crítico-reflexivo e instigador da sala de aula, e o professor deve estar preparado/capacitado para administrar essa 
“indisciplina” não concebendo-a como algo nocivo, mas necessário para o desenvolvimento do conhecimento/aprendizagem dos discentes.

Dentre as ações previstas/objetivos abarcadas/os no plano de trabalho do subprojeto, apresentado na seção anterior, estão:

2) [...] desenvolvimento da habilidade de gerenciamento de sala de aula;

4) organização de momentos de observação negociados com os professores responsáveis pela disciplina de língua inglesa [...] de forma a viabilizar [...] o estabelecimento da relação teoria/prática;

5)acompanhamento e avaliação das atividades dos bolsistas, buscando o princípio ação-reflexão-ação (UNIVERSIDADE FEDERAL DE GOIÁS, 2013, p. 23, grifo nosso).

Dessa forma, se faz necessário questionar se essas ações previstas no plano de trabalho foram de fato realizadas, pois, a partir dos excertos apresentados, foi possível perceber certa displicência quanto às orientações didáticas anteriores à atuação dos bolsistas em sala de aula, resultando em sentimentos desmotivadores e não contribuintes para a formação docente.

Ainda em relação à preparação teórico-metodológica prévia, haja vista que é enfatizado constantemente nas ações previstas/objetivos do plano de trabalho o estímulo ao perfil de professores crítico-reflexivos, é possível perceber que as impressões dos alunos quanto ao subprojeto vai contra a definição de aprendizagem reflexiva em Barcelos (2001), que consiste em:

[...] abrir a discussão a respeito de crenças, estratégias, estilos de aprendizagem aos alunos, para que eles mesmos possam refletir entre eles e com seus professores sobre sua cultura de aprender, sobre crenças de aprendizagem de línguas e como elas influenciam suas ações para aprender dentro e fora de sala de aula (BARCELOS, 2001, p. 86).

Entretanto, apesar do sentimento de despreparo quanto às orientações teóricometodológicas prévias, April e Helena (excertos 8 e 9) demonstraram maturidade quanto à prática docente, na medida em que buscaram por meios próprios de aprimorar sua autonomia, seja solicitando a ajuda de bolsistas mais experientes ou buscando auxílio de outros professores, e, dessa forma, conseguiram desenvolver o que lhes foi solicitado.

Esse é um aspecto importante, pois a aprendizagem, como atividade humana, é essencialmente social, ocorrendo mediante atividades de natureza prática (AUDI et al, 
2013). Sendo assim, as trocas de experiências desenvolvidas de maneira colaborativa, seja entre professores e alunos, alunos entre si, coordenadores e professores, "permitem a todos uma aprendizagem mais engajada e responsável, interessada nas aplicações interpessoais do exercício da profissão" (JORDÃO, 2013, p. 22). Entretanto, não deixa de ser responsabilidade do professor-coordenador e do professor-supervisor subsidiar essa colaboração e favorecer o amadurecimento teórico-metodológico, assim como a capacitação docente dos professores-estudantes atuantes no subprojeto.

No que tange às experiências contribuintes para a formação docente, os bolsistas do subprojeto evidenciaram: a) Experiência prévia ainda em período de graduação, b) Fomento da praxis docente e c) Preparação para pesquisa e apresentações em congressos acadêmicos, como podemos verificar nos excertos a seguir:

(Excerto 13) No início eu sentia ansiedade porque não sabia como seria, [...] eu sentia uma insegurança enorme, me perdia nas explicações, entrava em pânico etc. Agora eu me sinto muito mais segura em sala de aula, me sinto confortável com os alunos (April, questionário e relato de experiência).

(Excerto 14) O Pibid [...] dá-me uma ampla noção do que me espera quando eu começar a dar aulas. Oferece-me a oportunidade de aprender a lidar com os desafios de uma sala de aula antes de assumir uma. [...] Aprendi a trabalhar em equipe, e está me ajudando a me sentir mais confortável em sala de aula (Helena, questionário e relato de experiência).

(Excerto 15) Na época eu não sabia que isso [pluralidade de estilos de aprendizagem] era possível. [...] agora eu entendo o quanto é importante perceber estas diferenças em sala de aula, o material teórico trabalhado no Pibid me deu esta resposta. [...] Tenho pensado bastante sobre as coisas que o Pibid me ajudou e até então, sobre a sala de aula foram poucos os proveitos. O nosso subprojeto está trabalhando em uma pesquisa de ensino e aprendizagem e o que mais estou gostando é da parte de apresentar os nossos resultados nos congressos. Acredito que estou sendo bastante preparado para estas apresentações acadêmicas (Simão, questionário).

Portanto, podemos inferir que a participação no subprojeto Language and Literature contribuiu de forma considerável para a ressignificação de sentimentos de angústia e frustração suscitados no primeiro contato com a sala de aula, visto que nos excertos 13 e 14, April e Helena evidenciam que se sentem mais confortáveis e tranquilas em relação à sala de aula.

Ademais, a partir dos excertos 13, 14 e 15, é possível perceber que as contribuições advindas da participação no subprojeto se dão também a nível panorâmico, no sentido de oferecer aos professores em formação a oportunidade de vivência, bem como de 
reflexão e compreensão da futura profissão e dos processos de ensino/aprendizagem na esfera pública de educação, aspectos evidenciados constantemente nas ações previstas/objetivos do subprojeto.

Outrossim, no excerto 15, Simão evidencia a contribuição das leituras teóricas no decorrer de sua participação no subprojeto, ao passo que levaram o futuro professor a refletir sobre sua prática docente, assim como sobre o seu papel como educador, competência necessária no âmbito da docência. Ainda, no que tange às competências necessárias para a prática docente, as habilidades de aprender a lidar com os desafios da sala de aula e de trabalhar em equipes desenvolvidas ao longo da participação no subprojeto são evidenciadas por Helena no excerto 14. É relevante destacar que os fomentos das competências em questão estão previstos no plano de trabalho do subprojeto.

Em vista disso, apesar de Simão (excerto 15) evidenciar que foram poucos os proveitos tangentes à sala de aula, de maneira geral, as contribuições proporcionadas a partir da atuação dos bolsistas nas atividades do subprojeto são significativas para a prática docente dos professores em formação.

Dessa forma, a oportunidade dada aos bolsistas do subprojeto de estarem in loco anteriormente ao Estágio Supervisionado é fundamental no sentido de consolidar as bases da formação inicial dos participantes, haja vista que os períodos de experiência nos Estágios Supervisionados durante os cursos de licenciaturas não são suficientes para preparar totalmente os professores para a futura prática docente, o que resulta em sentimentos de frustração e despreparo ao assumirem responsabilidade sobre uma sala de aula, ocasionados pela ausência de um forte vínculo entre teoria e prática (DAWKINS; RITZ; LOUDEN, 2009). Portanto, parcerias entre escolas e professores em formação são ideais no sentido de recuperar o vínculo entre teoria e prática, assim como para oferecer apoio aos professores já formados e em formação (DAWKINS; RITZ; LOUDEN, 2009).

Outro aspecto modificador promovido pelo subprojeto, identificado a partir do excerto 15, é a preparação dos bolsistas para produções acadêmicas e apresentações em congressos, que consiste em uma contribuição relevante considerando tanto a tríplice ensino, pesquisa e extensão, imprescindível nas universidades brasileiras, como a 
divulgação dos trabalhos e consequente fomento do currículo dos participantes do subprojeto. Ademais, a participação em eventos acadêmicos é essencial para a construção da identidade professor-pesquisador crítico e reflexivo quanto a sua prática docente (JORDÃO, 2013), aspecto abarcado nas ações previstas/objetivos do subprojeto.

Não obstante, caso o subprojeto tenha focado mais em características acadêmicas do que na prática em sala de aula, como afirmado por Simão (excerto 15), fazendo com que os bolsista se sentissem mais preparados para congressos do que para a prática docente, esse pode não ter cumprido totalmente com objetivos gerais do Pibid e com as ações previstas/objetivos do plano de trabalho, visto que a formação docente e estabelecimento de relações entre teoria e prática em sala de aula são características principais tanto do Pibid quanto, consequentemente, do subprojeto em questão.

Portanto, diante do exposto, apesar da carência de orientações teóricometodológicas anteriores ao primeiro contato dos alunos com o contexto de ensino, a participação no subprojeto, considerando a aproximação da formação à docência e do âmbito público de educação básica e as oportunidades de experiências práticas proporcionadas aos bolsistas, foi relevante para consolidar as bases da formação docente dos participantes do subprojeto, no sentido de contribuir para o desenvolvimento de aspectos essenciais à prática docente, como o aprimoramento de capacidades de intervir de maneira profícua na educação básica, desenvolvimento do perfil do professorpesquisador, maior segurança e tranquilidade ao adentrar o âmbito de ensino, dentre outros aspectos contribuintes evidenciados no presente artigo.

\section{Considerações finais}

Por meio dos dados obtidos a partir da análise dos questionários e relatos de experiência apresentados nas seções anteriores, foi possível identificar contribuições consideráveis para a formação docente provenientes da atuação dos bolsistas no subprojeto Language and Literature, sendo elas:

1) auxílio financeiro ao licenciando, contribuindo para o envolvimento dos bolsistas de forma mais produtiva em sua área de estudos/atuação; 
2) aperfeiçoamento de habilidades como a facilidade de trabalhar em equipe, aspecto que contribui para o ensino/aprendizagem de forma colaborativa, bem como desenvolvimento de habilidades para lidar com desafios em sala de aula;

3) oportunidade de estabelecimento de relações entre teoria e prática, competência fundamental no que tange à atuação docente;

4) oportunidade de vivência, reflexão e compreensão do contexto público de educação, dos processos de ensino/aprendizagem, da prática docente e do papel do professor anteriormente ao Estágio Supervisionado;

5) preparação para produção acadêmica e apresentações em congressos, aspecto que contribui para a consolidação da identidade do professor crítico-reflexivo, assim como para o fomento do currículo acadêmico dos bolsistas, haja vista a relevância para prosseguimento nos estudos a nível de pós-graduação;

6) ressignificação de sentimentos desmotivadores decorrentes do primeiro contato com a sala de aula, oportunizando sentimentos de segurança e tranquilidade.

Em relação aos sentimentos desmotivadores decorrentes do primeiro encontro em sala de aula, os dados indicam certa carência de orientações didático-pedagógicas anteriormente ao adentramento dos bolsistas em sala de aula no âmbito do subprojeto, ocasionando sentimentos de desamparo, desconforto, frustração, desmotivação e impotência por parte dos professores em formação. Observou-se que tal carência de orientações resultou em mudanças de comportamento tangentes à atuação docente, como noções distorcidas quanto à indisciplina dos alunos, apreensão excessiva e rigidez metodológica. Nesse sentido, o coaching emocional ${ }^{1}$ (PADULA, 2016) e o acompanhamento do professor-coordenador e/ou professor-supervisor durante as atividades desenvolvidas pelos bolsistas, são estratégias essenciais no sentido de evitar ou ao menos auxiliar os bolsistas a lidarem com sentimentos desmotivadores oriundos de experiências frustrantes em sala de aula.

No que tange às ações previstas/objetivos presentes no plano de trabalho do subprojeto em questão, com exceção da carência de orientações didático-pedagógicas

\footnotetext{
${ }^{1}$ Padula (2016, p. 26) define coaching emocional como um processo transformacional colaborativo que pode ser conduzido entre professores formadores e professores em formação visando "alcançar objetivos relacionados ao bem-estar". Portanto, é "uma maneira de aplacar possíveis sofrimentos causados por instabilidades emocionais advindas de situações diversas" (PADULA, 2016, p. 26).
}

Revista Investigações, Recife, v. 32, n. 2, p. 207 - 227, Dezembro/2019 
apresentada no parágrafo anterior, em âmbito geral, o subprojeto cumpriu com as ações previstas/objetivos de forma satisfatória.

Por fim, é relevante evidenciar que apenas dois dos cinco bolsistas haviam tido experiência em sala de aula, o que é compreensível, haja vista a idade dos bolsistas, que possuem entre 18 e 25 anos, e o período da graduação em que se encontram, anterior ao Estágio Supervisionado. Considerando que as contribuições do subprojeto são provenientes da atuação prática dos bolsistas nas atividades desenvolvidas no subprojeto, esses alunos só teriam a oportunidade de adentrar o contexto educacional, no âmbito da graduação, a partir dos dois últimos anos do curso, por meio das disciplinas de Estágio Supervisionado. Sendo assim, fazer parte do Pibid proporcionou aos bolsistas maior tempo de experiência em sala de aula em relação aos graduandos ingressantes no mesmo período que os participantes do subprojeto.

\section{Referências}

ASSIS-PETERSON, A. A.; COX, M. I. P. Inglês em tempos de globalização: para além de bem e mal. Calidoscópio, São Leopoldo, v. 5, n. 1, p. 5-14, 2007. Disponível em: <http://revistas.unisinos.br/index.php/calidoscopio/article/view/5616>. Acesso em: 28 mar. 2017 .

AUDI, L. C. C. et al. Pibid de língua inglesa na UNEB campus X: algumas contribuições na formação docente. In: MATEUS, E; EL KADRI, M. S.; SILVA, K. A. (org.). Experiências de formação de professores de línguas e o Pibid: contornos, cores e matizes. Campinas: Pontes, 2013. p. 79-104.

BARCELOS, A. M. F. Metodologia de Pesquisa das Crenças sobre Aprendizagem de Línguas: estado da arte. Revista Brasileira de Linguística Aplicada, Belo Horizonte, v. 1, n. 1, p. 71-92, 2001. Disponível em: <http://www.scielo.br/pdf/rbla/vını/o5.pdf $>$. Acesso em: 28 fev. 2017.

, A. M. F. Reflexões acerca da mudança de crenças sobre ensino e aprendizagem de línguas. Revista Brasileira de Linguística Aplicada, Belo Horizonte, v. 7, n. 2, p. 109138, 2007. Disponível em: <http://www.scielo.br/pdf/rbla/v7n2/o6.pdf $>$. Acesso em: 2 mar. 2017. 
COELHO, H. S. H. "É possível aprender inglês na escola?" Crenças de professores e alunos sobre o ensino de inglês em escolas públicas. 2005. Dissertação (Mestrado em Linguística Aplicada) - Faculdade de Letras, Universidade Federal de Minas Gerais, Belo Horizonte, 2005. Disponível em: <http://www.bibliotecadigital.ufmg.br/dspace/handle/1843/ALDR6ACG69>. Acesso em: 19 jan. 2017.

DAWKINS, S.; RITZ, M. E.; LOUDEN, W. Learning by doing: preservice teachers as reading tutors. Australian Journal of Teacher Education, Perth, v. 34, n. 2, p. 40-49, 2009. Disponível em: <http://ro.ecu.edu.au/ajte/vol34/iss2/4>. Acesso em: 26 fev. 2017.

DÖRNYEI, Z. Research Methods in Applied Linguistics - Quantitative, Qualitative, and Mixed Methodologies. Oxford: Oxford University Press, 2007.

FADANELLI, S. B.; MONZÓN, A. J. Gêneros textuais datasheet e artigos científico em aulas de ESP: levantamentos léxico-estatísticos para fins educacionais. Domínios de Lingu@gem, Uberlândia, v. 11, n. 2, p. 351-378, 2017. Disponível em: $<$ http://www.seer.ufu.br/index.php/dominiosdelinguagem/article/view/36865/20121>. Acesso em: 7 ago. 2017.

FREIRE, P. Pedagogia da autonomia: saberes necessários à prática educativa. São Paulo: Paz e Terra, 1996.

GATTI, B. A. Os professores e suas identidades: o desvelamento da heterogeneidade. Cadernos de Pesquisa, São Paulo, n. 98, p. 85-90, 1996. Disponível em: <http://publicacoes.fcc.org.br/ojs/index.php/cp/article/view/798/809>. Acesso em: 25 mar. 2017 .

JENKINS, J. English as a lingua franca: from the classroom to the classroom. ELT Journal, Oxford, v. 66, n. 4, p. 486-494, 2012. Disponível em: <https://academic.oup.com/eltj/article/66/4/486/385078>. Acesso em: 31 mar. 2017.

JORDÃO, C. M. Letramento crítico, inglês como língua internacional e ensino: as marés do Pibid-Inglês da UFPR. In: MATEUS, E; EL KADRI, M. S.; SILVA, K. A. (org.). Experiências de formação de professores de línguas e o Pibid: contornos, cores e matizes. Campinas: Pontes, 2013. p. 21-47. 
LEFFA, V. J. Criação de bodes, carnavalização e cumplicidade. Considerações sobre o fracasso da LE na escola pública. In: LIMA, D. C. (org.). Inglês em escolas públicas não funciona? Uma questão, múltiplos olhares. São Paulo: Parábola, 2011.

, V. J. O ensino do inglês no futuro: da dicotomia para a convergência. In: STEVENS, C. M. T.; CUNHA, M. J. C. (org.). Caminhos e colheita: ensino e pesquisa na área de inglês no Brasil. Brasília: UnB, 2003. p. 225-250.

LIBÂNEO, J. C.; OLIVEIRA, J. F.; TOSCHI, M. B. A educação escolar no contexto das transformações da sociedade contemporânea. In: LIBÂNEO, J. C.; OLIVEIRA, J. F.; TOSCHI, M. B. Educação Escolar: políticas, estrutura e organização. 2. ed. São Paulo: Cortez, 2003. p. 66-106.

MARCONI, M. A.; LAKATOS, E. M. Fundamentos de metodologia científica. 5. ed. São Paulo: Atlas, 2003.

MATEUS, E. F.; EL KADRI, M. S.; GAFFURI, P. O que se pode ver da janela: uma análise do subprojeto de Letras-Inglês do Programa PIBID. Signum: Estudos da Linguagem, Londrina, v. 14, n. 1, p. 363-386. 2011. Disponível em: $<$ http://www.uel.br/revistas/uel/index.php/signum/article/view/8488/9228>. Acesso em: 8 nov. 2016.

MELLO, G. N. Formação inicial de professores para a educação básica: uma (re)visão radical. São Paulo em Perspectiva, São Paulo, v. 14, n. 1, p. 98-110. 200o. Disponível em: <http://www.scielo.br/pdf/spp/v14ni/g807.pdf $>$. Acesso em: 27 out. 2019.

MOITA LOPES, L. P. Inglês no mundo contemporâneo: ampliando oportunidades sociais por meio da educação. In: SIMPÓSIO DA TIRF (TESOL INTERNATIONAL RESEARCH FOUNDATION). São Paulo: mimeo, 2005.

MOITA, F. M. G. S. C.; ANDRADE, F. C. B. Ensino-pesquisa-extensão: um exercício de indissociabilidade na pós-graduação. Revista Brasileira de Educação, Rio de Janeiro, v. 14, n. 41, p. 269-280. 2009. Disponível em: < http://www.scielo.br/pdf/rbedu/v14n41/v14n41ao6.pdf $>$. Acesso em: 16 jan. 2017.

PADULA, B. C. Emoções de uma professora de Inglês de escola regular: o papel do coaching. 2016. Dissertação (Mestrado em Letras) - Universidade Federal de Viçosa, Viçosa, 2016. Disponível em: <http://www.locus.ufv.br/handle/123456789/8208>. Acesso em: 3 jul. 2017. 
SUGIMOTO, L. O tripé e o papel da universidade pública. Jornal da Unicamp, Campinas, 3-9 dez. 2007, $\quad$ p. $9 . \quad$ Disponível em: $<$ http://www.unicamp.br/unicamp/unicamp hoje/jornalPDF/ju382pagog.pdf $>$. Acesso em: 12 jan. 2017.

UNIVERSIDADE FEDERAL DE GOIÂS. Anexo II. Edital no 8o/2013/PIBID/UFG. Programa Institucional de Bolsa de Iniciação à Docência (PIBID). Subprojeto Letras Inglês: Language and Literature. Goiânia: Universidade Federal de Goiás, 2013. Disponível em: $<$ https://pibid.prograd.ufg.br/up/296/o/Subprojeto Letras Ingl\%C3\%AAs PIBID-

CAJ 2013.pdf . Acesso em: 4 nov. 2016.

VOLKMAN, E.; MENDES, T. C.; BACCON, A. L. P. Preparação para a docência: um estudo com alunos concluintes de um curso de licenciatura em matemática. In: REUNIÃO CIENTIIFICA REGIONAL DA ANPED - SUL, 11., 2016, Curitiba. Anais [...]. Curitiba: Setor de Educação da UFPR, 2016. Disponível em: <http://www.anpedsul2016.ufpr.br/portal/wpcontent/uploads/2015/11/EIXO6_ELIZABE TE-VOLKMAN-THAMIRIS-CHRISTINE-MENDES-ANA-LÚCIA-PEREIRA BACCON.pdf $\geq$. Acesso em: 27 out. 2019.

\footnotetext{
* Mestrando no Programa de Pós-Graduação em Estudos Linguísticos da Universidade Federal de Uberlândia (PPGEL/UFU).
} 